\title{
Resectable Hepatoblastoma
}

National Cancer Institute

\section{Source}

National Cancer Institute. Resectable Hepatoblastoma. NCI Thesaurus. Code C8642.

Hepatoblastoma amenable to surgical removal. 